\title{
Review of Don Ross's Philosophy of economics. Palgrave Macmillan, 2014, 341 pp.
}

JOHN B. DAVIS

Marquette University

University of Amsterdam

Don Ross begins his recent book by explaining why he regards analytical philosophy of science as "a barren enterprise" (p. 1). Analytical philosophy of science (derived from the twentieth century analytical philosophy tradition) accords the philosopher special expertise in the 'logic of concepts' and thus a unique responsibility for determining universal norms of thought for the sciences. This entails that technical concepts in science should be translated by the philosopher into more general, non-technical concepts-a kind of semantic reduction-purportedly in order to make the concepts of science more clear and precise, and thus more fully illuminate the achievements of science. However, Ross points out that this aim is at odds with the scientist's expectation that it is "the course of empirical discovery and theoretical refinement [that] will make her technical concepts more coherent and consistent" (p. 5). It is not pure conceptual analysis that advances philosophical understanding in science, Ross argues, but rather what scientists learn about their concepts from their investigation of the world. He accordingly takes up this vantage point in his book, and since the book is on the philosophy of science of economics, his starting point is "the course of empirical discovery and theoretical refinement" in economics itself that would make technical concepts in economics "more coherent and consistent".

Analytical philosophers of science have another ambition, Ross goes on, closely connected to their self-identification as experts in concept analysis. This is to promote the unity of science as an ideal and a particular way in which they believe the sciences 'fit together'. Here parallel to the semantic reduction idea is a strategy of 'boiling down' (p. 8) how different sciences explain into some single set of relationships-what Ross characterizes as ontological reduction and the simplest form of unification. For example: "This program encourages [scientists] to treat psychological structures and processes as just 
equivalent to neurophysiological structures and processes", such that neuroscience would displace or eliminate psychology (p. 9). Ross does not reject the ideal of unifying the sciences, but he does reject eliminativist unification strategies, and follows Philip Kitcher's more flexible view that scientists seek common 'argument patterns' without recourse to explicit methodological reflection and engage in a kind of "mutual disciplinary adaptation" (p. 10). He defends this view on pragmatic grounds and from his understanding of the history of science. The development of science is just too rich and complicated to bundle into simple conceptual packages and overarching schemas. Nonetheless, Ross still thinks philosophers of science and philosophers of economics have a role to play. Specifically, the philosopher of science/economics needs to be a "speculative, forward-looking historian of science with a special focus on interdisciplinary unification" (p. 13).

I will discuss the basis for Ross's understanding of interdisciplinary unification below. Here I flag Ross's position that what the philosophy of economics is principally about is interdisciplinary unification, and in particular economics' relation to psychology and sociology, because I think many interested in the philosophy of economics will find this view novel, counter-intuitive, and perhaps disagree with it. Indeed, many might rather say that the philosophy of economics is only about philosophical concepts and issues that are specific to economics, especially the concept of economic rationality. But for Ross preoccupation with the concept of economic rationality in the philosophy of economics is a "deep distraction and a red herring" (p. 24) which has perhaps done as much damage to the philosophy of economics as analytical philosophy has done to the philosophy of science. What we ought to do, he argues, is put aside our endless conceptual analysis of rationality and focus our attention on economics' scientific development in relation to its near neighbors.

This is what Ross himself does in this book after chapter one's discussion of the philosophy of economics and philosophy of science, devoting the second chapter to the evolution of the economics of markets in relation to its neighbors-mostly psychology-before 1980, and the last two chapters of the book, four and five, respectively to economics and individualistic psychology and economics and aggregative forms of social science, which includes macroeconomics and sociology (or social psychology). The third, middle chapter of the book presents his understanding of economic science around which his 
overall argument is built. His position on economics' relation to its neighbors follows from this understanding; it is that debates in the philosophy of economics "have been distorted by undue emphasis on the integration of psychology with economics by comparison with attention to the unification of economics with sociology" (p. 23). Thus, the most important question for the philosophy of economics is:

Are the principles of normative decision theory, or at least those principles most relevant to identification of relative opportunity costs and opportunity values, more closely approximated by individual people making choices in relative isolation, or by groups of people making choices in certain sorts of institutional contexts? (pp. 36, 186).

His answer is the latter, and thus he emphasizes that one of the 'main themes' of his book is that we should reject the idea "that all important properties [economics studies] 'boil down to' properties of individual people" (p. 2)-the standard microfoundations project. Indeed he rejects methodological individualism as a 'dogma' that economists would be better off abandoning (p. 20, see 114ff.). So what is his conception of economic science that underlies these views?

Ross calls it neo-Samuelsonianism. Following Paul Samuelson's development of revealed preference theory that completed twentieth century economics' long move away from psychology, economics in the latter half of the twentieth century became a science that operates at a level of aggregation above individuals.

Choice behavior, for a neo-Samuelsonian, is simply any behavior that is systematically (but typically stochastically) related to changes in incentives. The causal basis of choice behavior, at the individual scale but also at the aggregate scales that economists mainly study, includes channeling structures in the social and institutional environment that are often not explicitly represented in choosers' nervous systems, let alone in conscious awareness (pp. 251-252).

That is, economists study the ways in which markets themselves work in specific environments. The misconception that economics is about the individuals who participate in markets, then, stems from what Ross sees as a mis-reading of Leonard Savage's decision theory. Savage produced an idealized, 'small worlds' understanding of decisionmaking in which "institutionalized constraints tightly limit agents' goals and narrow the domains of the beliefs and conjectures that matter 
to their actions" (p. 239). It is still 'bedrock' theory for economics, and underlies the expansion of economics' toolkit to include game theory (discussed at length in chapter three), which Ross regards as a revolutionary advance in economic science. But Savage's 'small worlds' domain is not really the domain that economists investigate. Rather-here Ross follows Ken Binmore's cue-economists investigate 'large worlds' with:

Macro-scale labor markets, coalition-formation markets driven by politics and regulation (the main source of determinants for international trade), markets for innovation and entrepreneurship, financial markets, insurance and risk management markets-all of these abound with uncertainty (p. 239).

Savage's decision theory and Samuelson's revealed preference theory transfer well enough to these more complicated environments, but at the price of giving up the individualist orientation of the 'small world' frame for a more socially oriented approach. The economist, that is, needs to know a lot about the world that social sciences other than individualist psychology investigate in order to make good use of the modern achievements of economic science. A paradigmatic example for Ross in this regard is the "neo-Samuelsonian Nobel laureate Vernon Smith" whose concept of 'ecological rationality' provides a broader, more flexible framework of economic analysis (p. 239) than what Ross believes one will find in much of recent behavioral economics, and even neuroeconomics (about which he is quite critical-the main purpose of most of chapter four).

This, then, gives us a quick overview of Ross's understanding of economic science and his grounds for saying that the philosophy of economics should be concerned with economics' relationship to its near neighbors. However, the last section of chapter four (three quarters of the way through the book) suddenly opens up a new line of argument-though it has been implicit earlier in the book, and will not be new to those familiar with Ross's earlier works. The title of the section is: "Ecological rationality, externalism, and the intentional stance". When I reached this discussion, my first impulse as a reviewer was to say to readers that they ought to begin their reading of the book here rather than on page one. That is not really very practical advice, but I think the point is still basically fair since Ross's understanding of science and economics, and thus his philosophy of economics, cannot 
be easily separated from his long-standing commitment to a version of Daniel Dennett's philosophy.

Dennett (e.g., 1991) rejected internalist philosophies of mind that accounted for intentional behavior in terms of peoples' internal mental states on the grounds that 'looking inside' people is an incoherent exercise and one of the biggest dead-ends in the history of philosophy. In its place, Ross says, Dennett argued we should be concerned with "real patterns [of intentional behavior] at the scale of social organization, as opposed to approximate descriptions of states or events at the scale of individual psychology" (p. 245). In Ross's earlier book (2005) he labeled this view 'intentional-stance functionalism'.

It begins from a hypothesis about the function of mental concepts that caused them to evolve as a part of every normal person's behavioral repertoire. In order to coordinate their expectations, people must model one another as goal-directed systems. Furthermore, they must do so by reference to goals and means of achieving goals that they can share (p. 245; emphasis added).

The emphasis on function is important. Mental concepts develop from and are functional to people's interactions with one another, and thus one learns little about behavior by asking what people's motivations in isolation are. Rather, to understand behavior we need to look at whole populations of interacting individuals since it is at the aggregate level that we can observe patterns of behavior. This, Ross claims, is what sociologists are concerned with.

Thus the last chapter of the book turns to the issue of whether economics and sociology are converging. Its premise is that both are aggregative social sciences, but the hard work in developing the case for convergence lies in reconciling the different batteries of concepts employed in the two disciplines, concepts often seen in each discipline as radically opposed to one another. Ross's discussion at this point is accordingly prescriptive and programmatic, though he does examine arguments against unification from both sides. I will leave it to readers to review the details, and instead note how for Ross the matter ultimately depends on what he regards as the great failing of contemporary economics, namely many economists' continuing attachment to methodological individualism.

The problem, he argues, is that economists tend to be confused between normative individualism, which he supports, and descriptive 
individualism, which he believes is false-Ross calls himself a descriptive anti-individualist (p. 304). Normative individualism, the ethical promotion of individuality, is an achievement of modern societies and market economies derived from widespread recognition of the intrinsic and instrumental value of individuality. But descriptively speaking, people are not single, independent individuals in the sense most economists believe because, though

an economic agent is identified with a utility function [...] people's preferences are dynamically sculpted by socialization processes [and] an economic model of any relatively long stretch of a person's biography must depict the person as a succession of economic agents (p. 305).

This passage exhibits both the basic argument Ross wants to make and the tensions inherent in that argument. His vision of economics' achievement as a science is neo-Samuelsonian economics with individual utility functions and incentives. But those individual utility functions are not single individuals' utility functions in the sense most economists believe them to be, and yet they are still single individuals' utility functions. I am sympathetic to the idea that "people's preferences are dynamically sculpted by socialization" but do not see why people should still be thought to have individual utility functions. The only basis for this seems to be that this is the standard position in economics science, though that is hard to separate from the fact that most economists, Ross allows, are still methodological individualists.

Ross does recognize that it can be thought tautological to say that individuals "maximize 'their own' utility functions" since when "an economic agent is individuated in the first place by a utility function [...] there is no logical room for a utility function to 'belong' to any entity but the agent defined by reference to it" (p. 201) - a circularity argument I have made (Davis 2011, 6ff.). But he takes this to be a critique of egoism in standard theory rather than a problem about the arbitrariness involved in assigning individual utility functions to any kinds of economic agents as their 'own' utility functions. This is hardly an unimportant issue, moreover, since one of the principal achievements of any established science is getting causality right, and the assignment of utility functions to agents assigns them the status of individual causal agents. Why, then, should agents with preferences that 
are "dynamically sculpted by socialization" be assigned individual utility functions and the status of independent causal agents?

Ross brings a well-motivated philosophy of science critique of analytic philosophy to the philosophy of economics, and he uses Dennett persuasively to undermine individualist explanations in economics and to cast doubt on what psychology offers to economics. Less clear is how neo-Samuelsonian economics survives.

\section{REFERENCES}

Davis, John B. 2011. Individuals and identity in economics. Cambridge: Cambridge University Press.

Dennett, Daniel. 1991. Real patterns. Journal of Philosophy, 88 (1): 27-51.

Ross, Don. 2005. Economic theory and cognitive science: microexplanation. Cambridge (MA): MIT Press.

John Davis is professor of economics at Marquette University (USA) and professor of the history and philosophy of economics at Amsterdam University (Netherlands). His research interests include the theory of identity in economics, the normative dimensions of economics, the capability approach, pluralism, and complexity theory. He is currently writing on reflexivity in economics.

Contact e-mail: <john.davis@mu.edu> 